\title{
ANÁLISE DA APLICAÇÃO DA FERRAMENTA LEAN CONSTRUCTION ASSESSMENT TOOL (LCAT) EM UMA EMPRESA CONSTRUTORA GOIANA
}

\section{Analysis of the application of the tool Lean Construction Assessment Tool (LCAT) in a construction company in Goiás}

\author{
Tatiana Gondim do AMARAL ${ }^{1}$, Felipe Schmaltz ZALAF ${ }^{2}$, Lara Gomes Fleury TEIXEIRA ${ }^{3}$
}

Recebido em 01 de fevereiro de 2019; aceito em 05 de agosto de 2019; disponível on-line em 28 de dezembro de 2019.

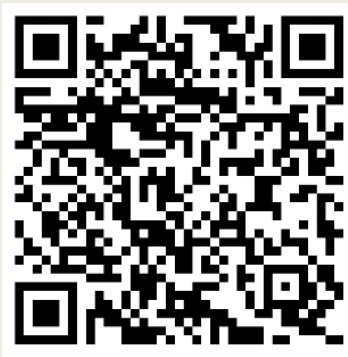

PALAVRAS CHAVE:

Lean;

Produção enxuta;

Construção enxuta;

Métodos avaliativos;

Pensamento enxuto.

\section{KEYWORDS:}

Lean;

Lean production;

Lean construction;

Evaluation methods;

Lean thinking.

RESUMO: As empresas estão investindo em melhorias na qualidade do seu produto e processo executivo e na redução de perdas e custos. O despertar sobre o Lean Thinking e suas possibilidades de aplicações torna-se importante como uma filosofia capaz de melhorar desempenhos e reduzir desperdícios de produção. A construção enxuta ainda não foi bem disseminada no Brasil, existem muitas empresas que não aplicam suas práticas ou que não as utilizam em todo o seu potencial. Diante do exposto, o objetivo principal deste trabalho é aplicar a ferramenta Lean Construction Assessment Tool (LCAT), desenvolvida por Camargo Filho (2017) e, através dessa aplicação, diagnosticar o lean score de uma construtora e analisar se a mudança de gestores entre empreendimentos de uma mesma empresa influencia no nível lean desta. A pesquisa é classificada como qualitativa-quantitativa, aplicada, exploratória e estudo de caso. Através da aplicação do questionário na empresa escolhida, se percebe que há várias práticas lean sendo aplicadas. Nem todas as práticas foram aplicadas da mesma forma pelos gestores, houve uma divergência em $25 \%$ dos itens analisados, o que mostra a grande influência que os gestores têm no nível lean da empresa. O lean score da empresa foi de $58 \%$, que segunda as faixas determinadas por Camargo Filho (2017) significa que a empresa tem um nível médio de implantação lean.

ABSTRACT: Companies are investing in improvements in the quality of their product and executive process and in reducing losses and costs. The awakening on Lean Thinking and its application possibilities becomes important as a philosophy that can improve performance and reduce production waste. Lean construction has not yet been widely disseminated in Brazil, many companies that do not apply their practices or do not use them to their full potential. Given the above, the main goal of this work is to apply the Lean Construction Assessment Tool (LCAT), developed by Camargo Filho (2017) and, through this application, to diagnose the lean score of a construction company and to analyze if the change of managers between enterprises of the same company influences the lean level from the company. The research classification is qualitative-quantitative, applied, exploratory and case study. Through the application of the questionnaire in the chosen company, we noticed that there are several lean practices being applied. Not all practices were applied in the same way by managers, there was a divergence in $25 \%$ of the analyzed items, which shows the great influence that managers have on the lean level of the company. The company's lean score was 58\%, which, according to Camargo Filho (2017), means that the company has an average level of lean deployment.

\footnotetext{
* Contato com os autores:

'e-mail: tatiana_amaral@hotmail.com (T. G. Amaral)

Professora Doutora da Escola de Engenharia Civil e Ambiental da Universidade Federal de Goiás - UFG.

2e-mail: feschmaltz@gmail.com (F.S.Zalaf)

Graduando em Engenharia Civil, Universidade Federal de Goiás.

3 e-mail: laragfleury@gmail.com ( L.G.F. Teixeira )

Graduanda em Engenharia Civil, Universidade Federal de Goiás.
} 


\section{INTRODUÇÃO}

Segundo dados do Instituto Brasileiro de Geografia e Estatística (IBGE), o Produto Interno Bruto (PIB) da Construção Civil no Brasil, em 2015, registrou uma queda de $7,6 \%$, o maior decréscimo dos últimos 12 anos (CBIC, 2016).

Essa redução está relacionada a um conjunto de fatores como a suspensão dos investimentos, o atraso nos pagamentos de obras contratadas e executadas para o Governo Federal, o aumento de impostos e a escalada da inflação (CBIC, 2015).

Mesmo com a baixa de investimentos na construção civil, as empresas não deixaram de buscar melhorias na qualidade do seu produto e processo executivo, além de investir na redução de perdas e custos. Em resposta a este momento de crise, observa-se no mercado da construção civil goiana um despertar para a filosofia enxuta.

A produção enxuta foi baseada nos princípios desenvolvidos pela Toyota. Tem como objetivos: potencialização do desempenho da produção aplicando técnicas e objetivos ao longo da linha de contemplação e do desenvolvimento do produto; organizar a montagem como um fluxo contínuo e confiável; aperfeiçoar a matéria final e buscar sempre a redução de perdas presentes no processo (HOWELL, 1999).

O Sistema Toyota de Produção (STP) foi o que teve a aplicação mais proeminente dentre os novos sistemas que surgiram. Baseando-se na busca pela eliminação de estoques e outros desperdícios, tal sistema se contempla através da produção de pequenos lotes, redução do tempo de montagens, uso de máquinas semiautomáticas e cooperação de fornecedores (KOSKELA, 1992).

Para aplicar a produção enxuta à construção civil, é necessário adaptar seus princípios às particularidades da construção, uma vez que a PE foi pensada inicialmente apenas para a manufatura. Koskela (1992) trabalhou nessa adaptação e desenvolveu um conjunto de princípios enxutos para a construção que ganhou o termo de construção enxuta (ETGES, 2012).

Cada vez mais as empresas da construção civil percebem a necessidade e importância em aumentar sua capacidade produtiva, a qualidade do seu produto e a redução de perdas e custos. Para conseguir atender essas necessidades, o setor passou a desenvolver melhorias no gerenciamento de seus processos (ETGES, 2012).

A Construção Enxuta ainda não foi bem disseminada no Brasil, existem muitas empresas que não aplicam suas práticas ou que não as utilizam em todo o seu potencial. Através do formulário que será aplicado nesse trabalho, é possível determinar o quão lean as empresas diagnosticadas são. O formulário também fornece informações sobre onde se pode melhorar para que a empresa se torne mais enxuta e evidencia os pontos fortes da empresa nos princípios da CE.

Dessa forma, observa-se como é importante que seja feito um estudo assertivo e contínuo sobre o tema para que a construção enxuta alcance cada vez mais usuários dentre as empresas brasileiras.

\section{OBJETIVOS}

O objetivo principal deste trabalho é aplicar a ferramenta Lean Construction Assessment Tool (LCAT), desenvolvida por Camargo Filho (2017) e, através dessa aplicação, diagnosticar o grau de implementação lean (lean score) e analisar se a mudança de gestores entre empreendimentos de uma mesma empresa influencia no nível lean da empresa.

\section{REVISÃO BIBLIOGRÁFICA}

\subsection{PRODUÇÃO E CONSTRUÇÃO ENXUTA}

O Sistema Toyota de Produção (STP), desenvolvido pela Toyota Motor Corporation, revolucionou a indústria automotiva a partir de 1950 e proporcionou a criação da filosofia de gestão da produção enxuta. Esse sistema se baseou 
na aplicação de duas teorias: o Just-in-Time (JIT) e o Total Quality Control (TQC) (WOMACK et al., 2004).

O JIT tenta reduzir e eliminar estoques, iniciando a produção quando ela realmente for demandada. Outro ponto importante desse método é a eliminação de desperdícios através da melhoria continua de operações, equipamentos e processos. Já o TQC busca garantir a qualidade e melhoria contínua dos produtos e processos desenvolvidos através do controle dos departamentos, das etapas operacionais e dos trabalhadores (KOSKELA, 1992).

Os cinco princípios propostos por Womack e Jones (1996), que constituem o Lean Thinking, foram: Valor, Fluxo de Valor, Fluxo, Puxar e Perfeição.

Koskela (1992) propôs uma adaptação da produção enxuta para a construção civil que se concretizou com os onze princípios que compõe a construção enxuta. Esses princípios são:

1. Reduzir a parcela de atividades que não agregam valor;

2. Aumentar o valor do produto através da consideração sistemática das necessidades dos clientes;

3. Reduzir a variabilidade;

4. Reduzir tempo de ciclo;

5. Simplificar e reduzir o número de passos e partes;

6. Aumentar a flexibilidade do produto;

7. Aumentar a transparência do processo;

8. Focar o controle no processo global;

9. Introduzir melhoria contínua no processo;

10. Balancear melhorias de fluxo com melhorias de conversão;

11. Benchmarking.

Os princípios de Koskela (1992) são de fácil entendimento, didaticamente bem definidos e facilitam a compreensão da filosofia enxuta para o ramo da construção civil, mas estão, muitas vezes, relacionados entre si o que permite que práticas ou ferramentas sejam atribuídas a mais de um princípio. Entretanto, os princípios de Womack e Jones (1996) são mais bem definidos e não se sobrepõem o que permite uma análise mais clara e precisa, apesar de serem mais gerais e abrangentes (CAMARGO FILHO, 2017).

\subsection{MÉTODOS AVALIATIVOS EXISTENTES}

Ao longo dos últimos anos, vários trabalhos foram desenvolvidos com o objetivo de produzir uma forma eficiente e prática de avaliação sobre o nível lean de empresas do ramo da construção civil. A seguir, será apresentado um resumo dos trabalhos desenvolvidos por Salem et al. (2006), Carvalho (2008), Hofacker et al. (2008), Valente et al. (2012), Etges (2012), Silva R., Amaral, Silva F. (2014) e Camargo Filho (2017).

Salem et al. (2006) aplicaram uma ferramenta desenvolvida especificamente para uma construtora em Ohio. A ferramenta, através de um checklist, avaliava seis técnicas lean: last planner, aumento da visualização, estudos preliminares, reuniões participativas, os $5 \mathrm{~S}$ 's e qualidade à prova de falhas. Nesse checklist, foram analisadas 24 práticas lean, cada uma recebeu uma pontuação de acordo com seu grau de implementação: nenhum (N), muito baixo (VL), baixo $(\mathrm{L})$, moderado $(\mathrm{M})$, alto $(\mathrm{H})$ e muito alto $(\mathrm{VH})$. Essa pontuação depois foi convertida para uma escala de 0 a 10 com a finalidade de se produzir um gráfico radar para identificar quais itens estavam prontos para serem implementados e quais precisavam de aprimoramento.

Uma equipe de pesquisa monitorou a implementação dessas técnicas na obra por 6 meses, fazendo 3 aplicações do checklist nesse período. Sendo a primeira na semana inicial do estudo, a segunda quando se atingiu um valor estabelecido pelo responsável da aplicação de cada técnica e a terceira na fase final de implementação. Os pesquisadores trabalharam com duas equipes diferentes, uma voltada para o planejamento e a outra para a execução.

Carvalho (2008) elaborou um questionário estruturado como protocolo de coleta de dados para avaliar o estado atual de construtoras em relação ao seu nível lean. O questionário foi dividido em seis partes, cada parte deve ser 
respondida por pelo menos uma pessoa da categoria à que está relacionada, sendo que as categorias são: diretoria, engenharia, operários, fornecedores, projetistas e clientes. O questionário foi baseado nos onze princípios de Koskela (1992) e para cada princípio foram elaboradas perguntas para determinar a presença e eficiência desses na empresa. Os entrevistados devem responder as perguntas classificando as características que ele vê na empresa, essa classificação vai de 0 a 3 , sendo 0 para inexistência do princípio e 3 para princípios efetivamente implementados e exibindo melhorias.

Foi feita uma aplicação piloto do questionário em uma empresa de pequeno porte para identificar possíveis falhas em sua estrutura. Após essa aplicação e avaliação de especialistas, o questionário passou por melhorias e foi, então, aplicado em quatro empresas. Três empresas eram de pequeno porte, sendo que duas afirmaram não ter construção enxuta, e a outra empresa era de médio porte e afirmou ter princípios lean. Com os resultados das entrevistas, foram feitos gráficos radar para identificar os pontos fortes e fracos das práticas lean em cada empresa, além de classificálas de acordo com o seu grau de implementação conforme escala criada pelo autor, baseada na pontuação obtida da classificação das perguntas.

Hofacker et al. (2008) fizeram uma pesquisa conjunta entre Universidades da Alemanha e do Brasil para desenvolver um questionário que combinava uma avaliação qualitativa, através de observação, com uma análise quantitativa para classificar as empresas de acordo com o seu nível lean. Eles desenvolveram a ferramenta para que fosse de rápida aplicação, que fornecesse de forma rápida e visual os resultados e que categorizasse o empreendimento de forma a sugerir melhorias. $\mathrm{O}$ questionário também pode ser aplicado em diferentes locais e tipos de construção. A aplicação deve ser conduzida por dois ou mais entrevistadores para reduzir ideias preconcebidas, facilitar a observação e realização das perguntas; logo após a visita ao canteiro, eles devem preencher o questionário individualmente e depois comparar e discutir os resultados para chegar a uma versão final.
A classificação foi dividida em 4 classes (a, b, c, d), sendo cada uma dividida em 3 subclasses (a, aa, aaa), a classificação foi feita de acordo com a percentagem lean alcançada. Eles se basearam nos onze princípios de Koskela (1992) e nos cinco princípios de Womack e Jones (1996) para construir o questionário. Esses princípios foram divididos em seis categorias no questionário, que são: foco no cliente; consciência de desperdício; qualidade; fluxo de material; organização, planejamento e fluxo de informação e melhoria contínua. O questionário apresentava 30 questão divididas entre as categorias, sendo que cada uma pode ser classificada de 0 (prática não aplicada) a 6 (prática totalmente aplicada).

Valente et al. (2012) fizeram um estudo de caso sobre o grau de aplicação, implementação e consolidação da construção enxuta em uma empresa brasileira localizada em Fortaleza (CE), que já apresentava a filosofia lean em sua organização. O checklist criado foi feito especificamente para essa empresa e, por isso, levou em consideração a história de implementação lean na empresa e suas metas e objetivos para a evolução da teoria lean. Esse checklist foi dividido em sete partes: Planejamento e Gestão da Produção, Kanbans, Jidoka, Fluxos, Produção, Transparência e Limpeza, Organização e Segurança. Cada item do checklist pode ser classificado de 0 a 3 ou, ainda, como uma prática não aplicável àquele canteiro. Com essa pontuação encontra-se o percentual de aplicação das práticas lean no canteiro.

A aplicação desse checklist foi feita através de auditorias internas periódicas como forma de motivar uma melhoria contínua através do monitoramento da atuação e evolução da filosofia lean nos canteiros. As auditorias foram feitas ao final de cada mês de Junho de 2011 a Outubro de 2011 em quatro obras. Os resultados das auditorias foram usados pelos engenheiros das obras e pelos gerentes da companhia para fazer um diagnóstico do que deveria ser melhorado no canteiro, impactando o processo de tomada de decisões tático e operacional e de decisões estratégicas. 
Etges (2012) criou um protocolo de auditoria de práticas lean que usava fontes de evidência para identificar a existência ou não dessas práticas. O protocolo apresentava 103 práticas divididas em 15 categorias. Essas categorias foram determinadas após extensa pesquisa nos artigos publicados de 1993 a 2010 no International Group for Lean Construction (IGLC), são elas: Recursos Humanos, Melhoria Contínua, Padronização do Trabalho, Segurança do Trabalho, Layout, Controle de Qualidade, Logística e Gerenciamento da Cadeia de Suprimento, Tecnologia da Informação e Comunicação, Produção Puxada, Gerenciamento Visual, Planejamento e Controle de Produção, Sustentabilidade, Gerenciamento de Projeto e Desenvolvimento do Produto, Controle de Custos e Fluxo Contínuo.

A aplicação de cada prática foi avaliada quantitativamente recebendo uma pontuação de 0 ; 0,5 ou 1,0; também existia a possibilidade de marcar a prática como não aplicável naquele cenário. Após a aplicação piloto, Etges viu a necessidade de ponderar as práticas de acordo com a importância delas em relação a teoria lean. Essa ponderação foi feita por um painel de especialistas em LC que deram um peso de 0 a 4 para cada prática, sendo 0 para práticas sem relação ao $L C$ e que poderiam ser retiradas do questionário.

Silva R., Amaral e Silva F. (2014) usaram uma ferramenta baseada no Fuzzy Inference System (FIS) para diagnosticar e monitorar matematicamente os conceitos subjetivos que surgem na implementação da filosofia lean em empresas da construção civil que estão fazendo a transição do pensamento tradicional para o pensamento enxuto. Para avaliar essa implementação, eles fizeram um questionário baseado nos onze princípios de Koskela (1992) e que avalia 55 práticas distribuídas entre os princípios. Uma pessoa previamente treinada executa o questionário verificando as práticas empregadas pela empresa.

Em seguida, modela-se o FIS colocando as variáveis de entrada e saída. Os valores de entrada são: tempo decorrido entre diagnósticos (X1), podem ser de primeiro, segundo e terceiro ciclo; e o nível de implementação de cada prática (X2), podem ser de baixo, médio ou alto nível de presença. $\mathrm{O}$ valor de saída é a pontuação $(\mathrm{Y})$ que representa o nível lean da empresa para cada princípio, vai de 0 a 10 . As pontuações dos princípios são combinadas para obter o Global Lean Score que permite uma comparação entre outras empresas e empreendimentos que aplicarem essa ferramenta.

O estudo de Camargo Filho (2017) será aprofundado no próximo item por se tratar do método avaliativo que será aplicado nesta pesquisa.

No Quadro 1 se encontra um resumo, de forma comparativa, dos questionários e ferramentas desenvolvidos pelos autores apresentados acima como forma de facilitar o entendimento sobre o tema.

\subsection{LEAN CONSTRUCTION ASSESMENT TOOL (LCAT)}

O objetivo de Camargo Filho (2017) é criar uma ferramenta capaz de avaliar o grau de implementação dos princípios da produção enxuta em empresas construtoras. A elaboração da Lean Construction Assesment Tool (LCAT) baseou-se em extensa pesquisa sobre as ferramentas criadas pelos autores supracitados.

A primeira versão foi feita a partir de uma adaptação e melhoria de um protocolo criado por Etges, Saurin e Bulhões (2013) e foi estruturada em 97 práticas dividas em 10 categorias. Sendo que cada prática poderia ser avaliada em 6 níveis (de 0 a 5). Essa versão foi usada em uma aplicação piloto para testar a aplicabilidade, clareza, fluidez, escala de avaliação e tempo de aplicação do questionário. Com a aplicação piloto, se percebeu que poderiam ser feitas algumas melhorias para facilitar o entendimento do formulário como realocar práticas que tivessem fontes de evidências semelhantes para que ficassem próximas. $\mathrm{O}$ autor continuou com o processo de aplicar o formulário em empresas construtoras e com a análise sobre possíveis melhorias que facilitassem a sua aplicação e entendimento. 
QUADRO 1: Resumo dos métodos avaliativos existentes de práticas lean

\begin{tabular}{|c|c|c|c|c|c|c|c|}
\hline & $\begin{array}{l}\text { Salem et al. } \\
(2006)\end{array}$ & Carvalho (2008) & $\begin{array}{c}\text { Hofacker et al. } \\
\text { (2008) } \\
\end{array}$ & Valente et al. (2012) & Etges (2012) & $\begin{array}{l}\text { Silva R., Amaral, } \\
\text { Silva F. (2014) }\end{array}$ & Camargo Filho (2017) \\
\hline Avaliação dos princípios & Não há definição & Koskela (1992) & $\begin{array}{c}\text { Koskela (1992) e } \\
\text { Womack \& Jones } \\
(1996)\end{array}$ & $\begin{array}{c}\text { Koskela (1992) e } \\
\text { Womack et al. } \\
(1990)\end{array}$ & $\begin{array}{c}\text { Womack \& Jones } \\
\text { (1996) }\end{array}$ & Koskela (1992) & Não há definição \\
\hline $\begin{array}{l}\text { Ponderação das práticas } \\
\text { em relação aos princípios }\end{array}$ & Não aplicado & Não aplicado & Não aplicado & Não aplicado & $\begin{array}{l}\text { Práticas ponderadas } \\
\text { a partir de pesos } \\
\text { atribuídas por } \\
\text { especialistas }\end{array}$ & Não aplicado & $\begin{array}{c}\text { Práticas ponderadas a } \\
\text { partir de pesos } \\
\text { atribuídas por } \\
\text { especialistas }\end{array}$ \\
\hline Número de práticas & 24 & 204 & 30 & 55 & 103 & 55 & 84 \\
\hline Número de categorias & 6 & 6 & 6 & 7 & 15 & 11 & 4 \\
\hline Aplicação piloto & Não & Sim & Sim & Não & Sim & Sim & Sim \\
\hline $\begin{array}{c}\text { Escala de avaliação das } \\
\text { práticas }\end{array}$ & Seis níveis & $\begin{array}{l}\text { Quatro níveis } \\
\qquad(0 \text { a } 3)\end{array}$ & $\begin{array}{l}\text { Sete níveis } \\
\qquad(0 \text { a } 6)\end{array}$ & $\begin{array}{l}\text { Cinco níveis } \\
(0 \text { a } 3+\mathrm{NA})\end{array}$ & Três níveis & $\begin{array}{l}\text { Onze níveis } \\
\qquad(0 \text { a 10) }\end{array}$ & $\begin{array}{l}\text { Quatro níveis } \\
(0 \text { a } 2+\mathrm{NA})\end{array}$ \\
\hline Duração de aplicação & Não informado & $\begin{array}{c}45 \text { min por } \\
\text { entrevistado }\end{array}$ & $1,5 \mathrm{~h}$ & Não informado & $4 h$ & Não informado & $50 \mathrm{~min}$ \\
\hline Número de aplicações & $\begin{array}{c}\text { Três na mesma } \\
\text { obra }\end{array}$ & Quatro & Não determinado & $\begin{array}{c}\text { Mensais em } 4 \\
\text { empreendimentos } \\
6 \text { no total }\end{array}$ & Uma & Quatro & Dezenove \\
\hline $\begin{array}{l}\text { Desenvolvido para uma } \\
\text { empresa específica }\end{array}$ & Sim & Não & Não & Sim & Não & Não & Não \\
\hline Tipos de empresa & Construtora & $\begin{array}{c}\text { Construtoras de } \\
\text { pequeno e } \\
\text { médio porte } \\
\end{array}$ & $\begin{array}{c}\text { Construtoras com } \\
\text { ênfase em edifícios } \\
\text { altos }\end{array}$ & Incorporadora & $\begin{array}{l}\text { Incorporadora e } \\
\text { Construtora }\end{array}$ & $\begin{array}{l}\text { Construtoras e } \\
\text { Centro de Gestão }\end{array}$ & Construtoras \\
\hline $\begin{array}{c}\text { Tipos de } \\
\text { empreendimento }\end{array}$ & Estacionamento & $\begin{array}{l}\text { Industriais, } \\
\text { residenciais, } \\
\text { agência bancária }\end{array}$ & Não informado & $\begin{array}{l}\text { Residenciais } \\
\text { multifamiliares }\end{array}$ & Residencial & $\begin{array}{l}\text { Edificações } \\
\text { verticais }\end{array}$ & $\begin{array}{l}\text { Residenciais } \\
\text { multifamiliares }\end{array}$ \\
\hline Local de aplicação & Ohio & $\begin{array}{l}\text { Curitiba, Porto } \\
\text { Alegre e Belém }\end{array}$ & $\begin{array}{l}\text { Alemanha e Brasil } \\
\text { (Curitiba) }\end{array}$ & Fortaleza & Porto Alegre & Goiânia & Goiânia \\
\hline
\end{tabular}


A última versão do formulário apresenta 84 práticas divididas em 4 categorias (Gestão da Qualidade, Gestão da Cadeia de Suprimentos, Planejamento e Controle da Produção e Gestão de Projetos). O critério de avaliação passou a ter quatro níveis, de 0 a 2 e um nível de prática não aplicável.

No início, Camargo Filho (2017) se baseou nos cinco princípios da mentalidade enxuta descritos por Womack e Jones (1996). Conforme foram feitas as aplicações dos questionários, o autor percebeu que existiam princípios e práticas relacionadas entre si e que se sobrepunham levando a necessidade de uma mudança na forma como eles são analisados. Assim, a versão final do formulário não segue a divisão dos princípios feita por Womack e Jones (1996) e nem os princípios propostos por Koskela (1992).

\section{METODOLOGIA}

\subsection{CLASSIFICAÇÃO}

A classificação da pesquisa é feita baseada em quatro aspectos: abordagem, natureza, objetivos e procedimento.

No que se refere à abordagem, uma pesquisa pode ser classificada como qualitativa ou quantitativa. Esta pesquisa, em específico, apresenta caráter mútuo, ou seja, qualitativoquantitativo. Deseja-se obter uma compreensão e explicação do tema estudado simultaneamente com uma coleta de dados e atribuição de valores dos conceitos presentes no formulário de Camargo Filho (2017).

Quanto à natureza, a pesquisa é classificada como aplicada. Sendo uma pesquisa aplicada aquela que tem o objetivo de resolver problemas ou necessidades concretas e imediatas (APPOLINÁRIO, 2004), esta pesquisa se encaixa em tal classificação por buscar conhecimentos acerca do pensamento lean e aplicação do formulário de Camargo Filho (2017) que será utilizado em diversos contextos da construção civil.
Já no âmbito dos objetivos, esta pesquisa é do tipo exploratória, pois visa proporcionar familiaridade com o tema, tornando-o explícito e permitindo a construção de hipóteses, envolvendo, para isso, levantamento bibliográfico prévio (GIL, 1991).

Por fim, no que diz respeito aos procedimentos, a pesquisa é classificada como sendo de estudo de caso. O estudo de caso torna possível a investigação de uma realidade delimitada para apreender características significantes do evento em questão (YIN, 1990). Como o formulário de Camargo Filho (2017) será aplicado em empreendimentos diferentes, a pesquisa investigará mais de um caso, justificando a nomenclatura designada.

\subsection{DELINEAMENTO}

As etapas que compreendem o delineamento da pesquisa estão indicadas na Figura 1:

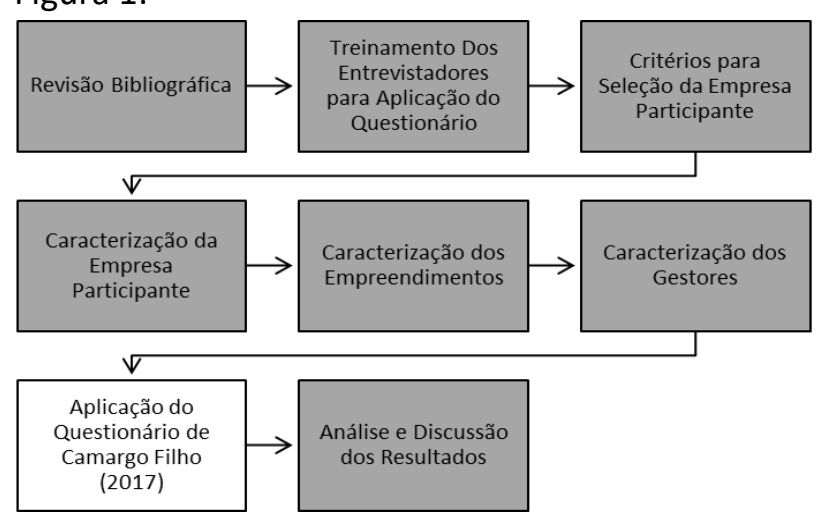

FIGURA 1: Delineamento da pesquisa. FONTE: Do autor.

Nas próximas seções deste capítulo serão apresentados detalhes de cada etapa.

\subsubsection{Revisão Bibliográfica}

Na revisão bibliográfica foram abordados os princípios da construção enxuta e da produção enxuta. Também foi apresentada uma relação de questionários que avaliam o nível de implementação dos princípios lean. Outras bibliografias pesquisadas estão relacionadas aos termos e práticas presentes no questionário para melhor compreendê-lo. 


\subsubsection{Treinamento dos Entrevistadores para Aplicação do Questionário}

O treinamento dos aplicadores foi realizado durante a disciplina optativa "Construção Industrializada" ofertada no curso de Engenharia Civil da Universidade Federal de Goiás (UFG).

Com aulas ocorrendo uma vez por semana durante todo o semestre letivo, com duração de uma hora e 40 minutos, os alunos receberam treinamento para aplicação do formulário ao final do curso.

O treinamento praticado na disciplina foi dividido em quatro fases: introdução à temática, explicação dos princípios da construção enxuta, estudo do questionário e o treinamento prático.

A introdução à temática foi uma forma de contextualizar e familiarizar os alunos com as bases teóricas do tema, explicando as origens do Sistema Toyota de Produção (STP), princípios da produção enxuta (PE) e a sua importância no cenário atual da construção civil.

$\mathrm{Na}$ segunda fase, foi dado ênfase à construção enxuta (CE). Com duração de quatro aulas e carga horária de oito horas, foram explicados princípios e ferramentas fundamentais da CE, referenciando os autores citados na etapa de revisão bibliográfica e relacionando com exemplos práticos do cotidiano de um empreendimento. $\mathrm{O}$ objetivo desta etapa foi capacitar os alunos à compreensão do questionário.

A terceira etapa, chamada de estudo do questionário de Camargo Filho, foi acompanhada da disponibilização do questionário para cada aluno juntamente com um manual de aplicação. Nesta etapa, com duração de três aulas e carga horária de seis horas, foi realizada a explicação de cada item do questionário e uma orientação do porquê da disposição dos mesmos juntamente com uma fonte de evidência no local do empreendimento para avaliação.

\subsubsection{Critérios para Seleção da Empresa Participante}

Antes da aplicação do questionário de Camargo Filho (2017), foi necessária a escolha da empresa participante do processo. Nesta etapa não foi utilizado nenhum método estatístico, ou seja, baseou-se num método não probabilístico intencional, no qual predominou critérios que a empresa participante deveria atender.

Dentre os critérios destacados, os mais relevantes foram: 1) Possuir interesse em participar da pesquisa; 2) Estar localizada na cidade de Goiânia; 3) Ser Incorporadora e/ou Construtora de grande porte; 4) Possuir certificações relacionadas ao Sistema de Gestão da Qualidade e/ou Ambiental; 5) Possuir obras em execução; 6) Ser integrante da comunidade da construção do Sindicato da Indústria da Construção do Estado de Goiás (SINDUSCON-GO); e, 7) Facilidade de acesso e contato com os funcionários da empresa.

O primeiro critério, denominado como interesse em participar da pesquisa, é essencial e autoexplicativo, não necessitando de detalhamentos acerca do mesmo.

A localização, segundo critério, trata-se de um limitante físico e temporal presente na pesquisa. Buscando a realização em tempo hábil e considerando que o treinamento dos entrevistadores foi feito na cidade de Goiânia, buscou-se uma empresa que fosse localizada nesta capital.

Considerando uma indústria de grande porte aquela que possui 500 ou mais funcionários (SEBRAE, 2013) a busca por Incorporadora ou Construtora desta classificação é consequência do objetivo principal desta pesquisa: aplicar o questionário de Camargo Filho (2017).

Outro critério importante na seleção da empresa participante foi a necessidade de que a mesma apresentasse sistemas de gestão implantados, podendo ser Sistemas de Gestão de Qualidade (SGQ), Sistema de Gestão Ambiental (SGA), ISO 9001 ou Programa Brasileiro da Qualidade e Produtividade do Habitat (PBQP-H).

O quinto critério, empresa possuir obra em execução, se faz necessário para a aplicação imediata do questionário. Se a empresa escolhida não estivesse em atividade, não se tornaria viável avaliar o seu grau de implementação da construção 
enxuta.

O fato de a empresa ser vinculada à Comunidade de Construção - GO permite afirmar que a mesma possui preocupações nos quesitos de eficiência e competitividade de mercado dando ainda mais credibilidade à pesquisa.

Outro fator que contribuiu para a escolha da empresa, além do fato dela atender a todos os critérios apresentados anteriormente, foi a facilidade de acesso aos funcionários da participante uma vez que um dos autores do trabalho faz estágio na mesma.

\subsubsection{Caracterização da Empresa Participante}

A empresa participante do estudo é uma construtora de grande porte que atua desde 1986 em Goiânia. A empresa já entregou 45 empreendimentos, edifícios residenciais na sua maioria, tem 797.004,89 metros quadrados construídos e gera mais de 700 empregos diretos. Tem certificações ISO 9001 e PBPQ-h.

A construtora já aplica algumas práticas lean como: brainstorming, check-list, diagrama de causa e efeito, diagrama de Pareto, fluxograma e gráficos de controle.

A empresa está executando quatro obras atualmente, o formulário LCAT foi aplicado em todas as quatro.

\subsubsection{Caracterização dos Empreendimentos}

Os empreendimentos analisados estavam em diferentes etapas de construção. Eles possuem uma estimativa da quantidade de funcionários, próprios e terceirizados, que vão passar pela obra, em quantidades semelhantes. O Quadro 2 apresenta mais detalhes.

\subsubsection{Caracterização dos Gestores}

A caracterização dos gestores foi necessária para avaliar a formação e experiência de cada um. Todos tiveram uma formação parecida e buscaram cursos de especialização e complementação após a graduação em Engenharia Civil como podemos ver no Quadro 3.

\subsubsection{Aplicação do Questionário de Camargo Filho (2017)}

Tentando evitar ao máximo o efeito da influência do entrevistador no resultado final, optou-se pela aplicação do questionário pelos dois pesquisadores, responsáveis por esta pesquisa.

Conhecendo a política da empresa de padronização de algumas práticas para todos seus empreendimentos através do trabalho realizado no escritório, a aplicação da ferramenta Lean Construction Assessment Tool (LCAT) de Camargo Filho (2017) foi realizada cinco vezes: sendo uma em cada empreendimento e uma no escritório.

Com o intuito de evitar repetições e permitir a fluência da aplicação da ferramenta Lean Construction Assessment Tool (LCAT) de Camargo Filho (2017), o questionário foi dividido em 59 práticas que deveriam ser respondidas pelos gestores de cada empreendimento e 37 práticas que deveriam ser respondidas pelos responsáveis pelo escritório, já considerando um total de 12 práticas que deveriam ser respondidas por ambos.

Quanto ao tempo de aplicação, no escritório a aplicação teve duração de 15 minutos. Já nos empreendimentos, houve uma variação de 30 minutos até 1 hora, ocasionada pela disponibilidade de tempo livre do gestor no momento da aplicação da ferramenta. Entretanto, o tempo médio de aplicação nos empreendimentos foi de 40 minutos.

A pontuação de cada prática da ferramenta Lean Construction Assessment Tool (LCAT) de Camargo Filho (2017) foi feita de modo separado por cada um dos pesquisadores. Ao final de todas as aplicações, houve uma reunião entre os mesmos para definir um resultado final das práticas em que existiu divergência. De todas as aplicações realizadas, houve divergência em apenas 5 \% das pontuações.

O questionário de Camargo Filho (2017) está disponível no ANEXO A, em conjunto com seu manual de aplicação no ANEXO B. 


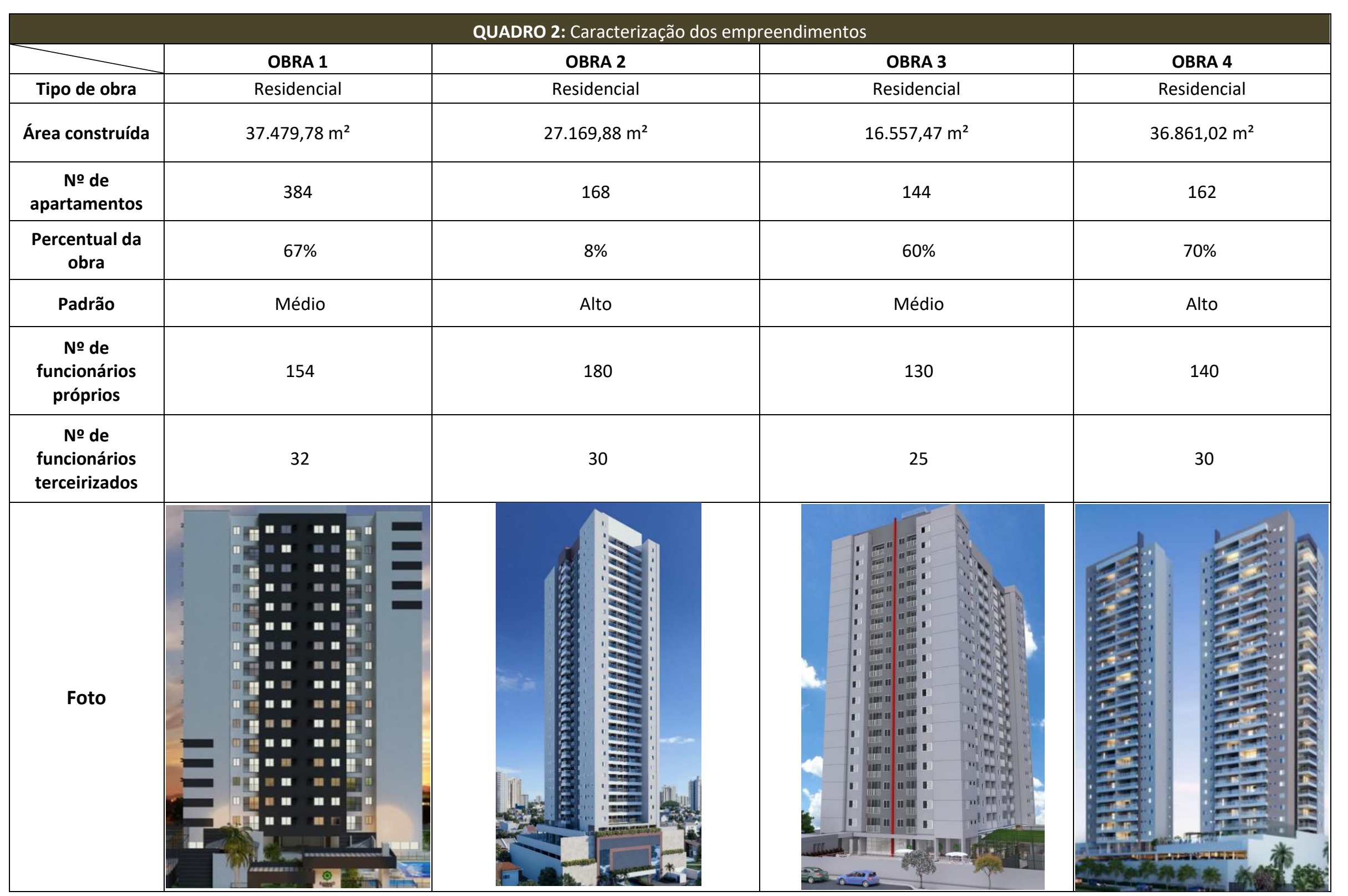




\begin{tabular}{|c|c|c|c|c|c|c|c|}
\hline & Idade & $\begin{array}{l}\text { Instituição } \\
\text { de ensino }\end{array}$ & $\begin{array}{c}\text { Formação } \\
\text { complementar }\end{array}$ & Área de formação & $\begin{array}{l}\text { Conhecimentos } \\
\text { específicos }\end{array}$ & $\begin{array}{l}\text { Tempo de } \\
\text { graduação }\end{array}$ & $\begin{array}{c}\text { Tempo } \\
\text { de } \\
\text { empresa }\end{array}$ \\
\hline OBRA 1 & 35 & UFG & Especialização & $\begin{array}{c}\text { Gestão e } \\
\text { Gerenciamento } \\
\text { de Obras }\end{array}$ & - & 12 anos & 13 anos \\
\hline OBRA 2 & 29 & PUC-GO & Mestrado UFG & Planejamento & MS Project & 7 anos & 10 anos \\
\hline OBRA 3 & 29 & UFG & $\begin{array}{l}\text { Pós graduação } \\
\text { IPOG }\end{array}$ & $\begin{array}{c}\text { Gestão e controle } \\
\text { de obras }\end{array}$ & - & 5 anos & 7 anos \\
\hline OBRA 4 & 31 & UFG & Especialização & $\begin{array}{c}\text { Gestão e } \\
\text { Gerenciamento } \\
\text { de Obras }\end{array}$ & MS Project & 8 anos & 9 anos \\
\hline
\end{tabular}

FONTE: Do autor.

\subsubsection{Análise de Dados e Discussão de Resultados}

Diante da aplicação do questionário em diversos empreendimentos de uma mesma empresa, foi possível, além de aplicar ferramenta Lean Construction Assessment Tool (LCAT) de Camargo Filho (2017), verificar o conhecimento do pensamento lean por parte da construtora goiana envolvida, diagnosticando o grau de implementação da construção enxuta na empresa e analisar a influência dos gestores de obras no nível lean.

Para isso, os resultados obtidos através das entrevistas foram tabulados no formulário e foi possível gerar, com o auxílio do programa Microsoft Excel, resultados gráficos para melhor análise da pesquisa.
Os resultados gráficos estão apresentados em duas principais formas: histograma e gráfico Radar. O histograma referenciou, por empreendimento pesquisado e pela empresa, a média de cada categoria analisada. Já o formato Radar, teve construção concebida para mostrar a média aritmética, também por empreendimento, de dois aspectos: por categorias e do questionário como um todo.

De forma a complementar os resultados gráficos, também foi feita, em forma de tabela, uma pontuação do grau de implementação lean (lean score) da empresa e de cada obra, sendo obtidas através de uma média aritmética dos resultados obtidos em cada categoria. Com esse valor, classificou-se a empresa de acordo com as faixas de lean score estabelecidas por Camargo Filho (2017), como segue no Quadro 4.

\begin{tabular}{|c|c|}
\hline \multicolumn{2}{|c|}{ QUADRO 4: Faixas Lean Score (Camargo Filho, 2017) } \\
\hline Grau de Implementação & Lean Score \\
\hline Muito Pouco & $0-20 \%$ \\
\hline Pouco & $20-40 \%$ \\
\hline Médio & $40-60 \%$ \\
\hline Alto & $60-80 \%$ \\
\hline Muito Alto & $80-100 \%$ \\
\hline
\end{tabular}

FONTE: Adaptado de Camargo Filho (2017). 
Foi feita também uma caracterização dos gestores de cada obra com a finalidade de entender possíveis diferenças de resultados, buscando explicações em instituição de ensino em que foi feita a graduação, formação complementar, área de formação, conhecimentos específicos e tempo de graduação e empresa. Também foi feita uma análise de equivalência entre as notas das categorias dos empreendimentos, a fim de verificar o quão divergente os empreendimentos são entre si.

$$
\text { Os resultados obtidos foram }
$$
discutidos e analisados a fim de se verificar a eficácia das melhorias feitas no decorrer de sua formulação, garantindo assim sua aplicabilidade como uma ferramenta que minimize a necessidade de um conhecimento específico do tema para implementação da construção enxuta.

\section{ANÁLISE E DISCUSSÃO DE RESULTADOS}

A equivalência apresentada entre as notas dos itens dos empreendimentos foi de $75 \%$ o que significa que $25 \%$ dos itens tiveram divergências sobre as notas que receberam.

As médias das notas das categorias de cada obra e a média obtida para a empresa são apresentadas na Figura 2, onde é feita uma comparação entre os empreendimentos com relação à empresa, através de um gráfico de barras.

As médias das notas dos itens por categoria e a nota média total de cada obra são apresentadas na Figura 3, onde é feita uma comparação entre os empreendimentos, através de um gráfico radar.

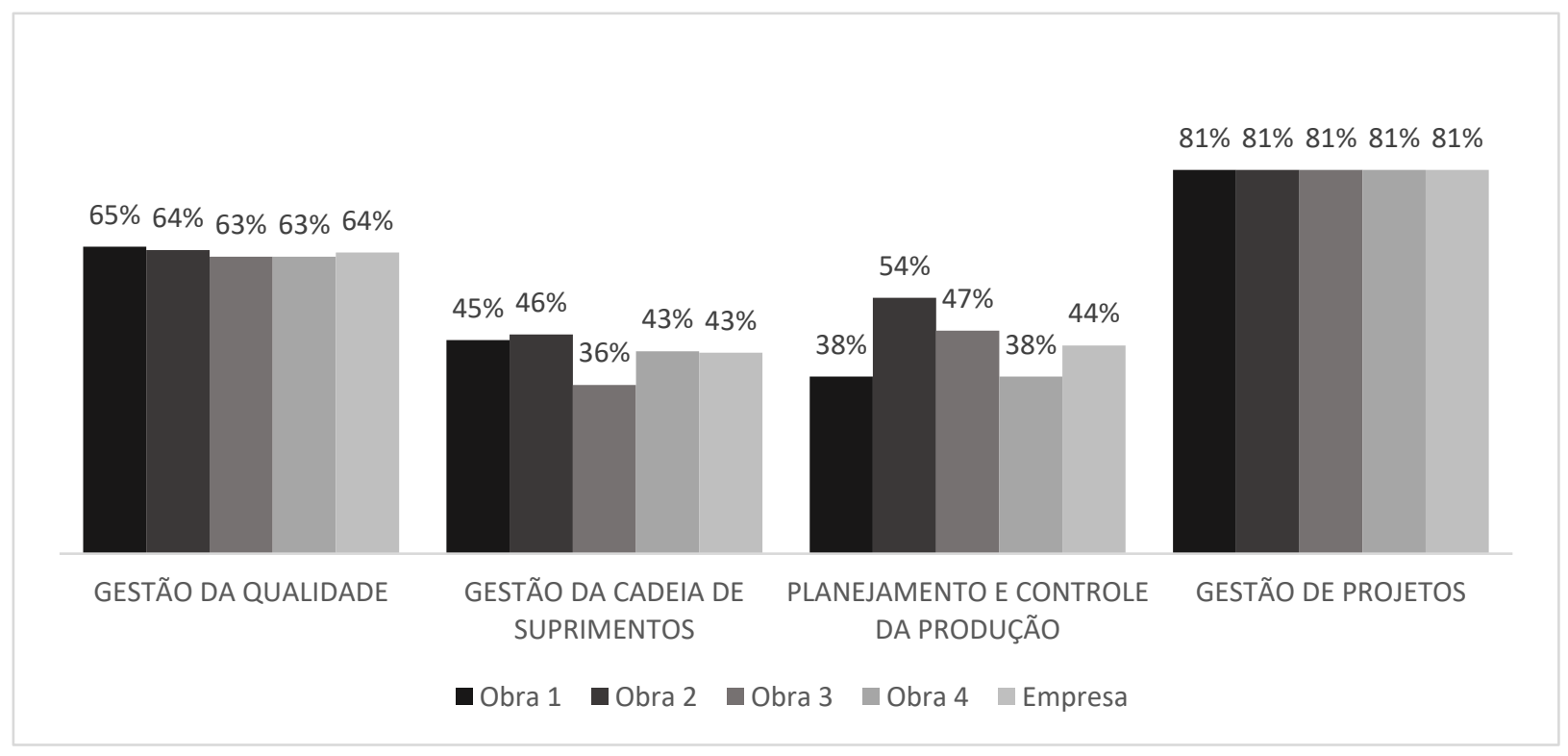

FIGURA 2: Gráfico de barras das médias das categorias FONTE: Produzido pelos autores. 


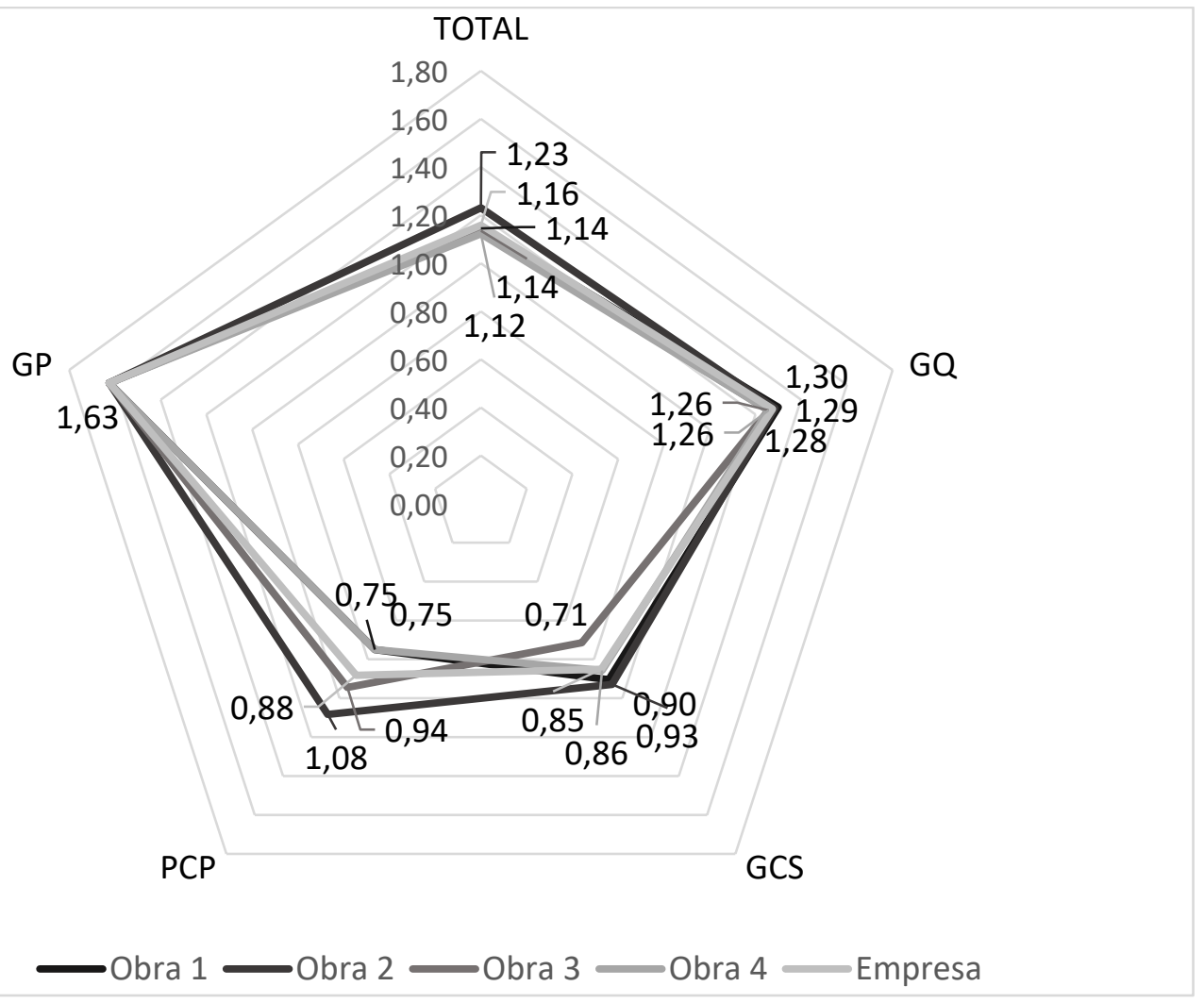

FIGURA 3: Gráfico radar das médias dos itens por categoria. FONTE: Produzido pelos autores.

A equivalência encontrada entre as notas dos itens dos empreendimentos foi de $75 \%$ o que significa que $25 \%$ dos itens tiveram divergências sobre as notas que receberam, ou seja, pelo menos um dos gestores faz ou deixa de fazer algo que os outros fazem. Isso mostra o quanto a mudança de gestor de uma obra para a outra influencia nas práticas do lean construction aplicadas no canteiro.

Em relação às qualificações dos gestores, não se observou grandes diferenças entre eles. Todos possuem alguma qualificação adquirida além da formação básica da graduação em engenharia civil, tais como lato sensu $e$ stricto sensu. Apesar de terem essas especificações, alguns gestores, como também engenheiros do escritório entrevistados, apresentaram dificuldade para entender $\mathrm{o}$ conteúdo presente no questionário no momento da aplicação. A dificuldade no entendimento se deve ao fato de não conhecerem os termos específicos de algumas ferramentas lean, principalmente por não terem visto nada relacionado à construção enxuta durante a graduação.

As categorias de Gestão da Cadeia de Suprimentos e Planejamento e Controle da Produção apresentaram a maior discrepância entre as notas dos itens, a categoria da Gestão da Qualidade apresentou algumas divergências e a Gestão de Projetos teve os itens com a mesma nota para todas as obras.

A categoria Gestão de Projetos teve as mesmas notas nos itens, assim, ficou com a mesma média para todos os quatro empreendimentos, sendo a média de 1,63 em um total de 2,0. Isso se deve ao fato da pessoa responsável pelas atividades relacionadas à essa categoria ficar no escritório da empresa e aplicar os mesmos processos para todas as obras.

A nota dessa categoria foi muito alta, atingiu $81 \%$ de aplicação das práticas dessa categoria. Uma vez que a empresa tem processos totalmente implantados para quase todos os itens. Apenas a comunicação direta entre os projetistas e engenheiros de obra e o uso de realidade 
aumentada para testar novos itens não ocorrem. A empresa está começando a utilizar o BIM para compatibilizar os projetos, portanto a prática ainda é parcialmente aplicada.

As médias das obras com relação à Gestão da Qualidade ficaram bem próximas, sendo de 1,3 para a obra 1, 1,29 para obra 2 e 1,26 para obras 3 e 4. Isso ocorre pois a empresa tem processos bem definidos para os itens avaliados nessa categoria como treinamentos e capacitação dos funcionários para controlar sua própria produção com relação às atividades que eles vão executar; benchmarking interno através de reuniões mensais e externo com visitas a outros canteiros; avaliação do desempenho da equipe através de Fichas de Verificação de Serviços (FVS); organização do ambiente de trabalho com checklist feito pela área de Segurança do Trabalho dentro do canteiro.

Um dos pontos que fizeram a nota dos empreendimentos cair nessa categoria está relacionada à solução de problemas. Não há documentação que defina o grupo de solução de problemas e suas reuniões dentro da obra. Quando questionados sobre o método utilizado para encontrar as causas raízes, as respostas estavam relacionadas aos problemas encontrados nas FVS's, onde identificavam o problema e arranjavam uma solução para ele sem investigar a real causa do problema. Nenhum dos engenheiros mencionou as práticas brainstorming ou diagrama de causa e efeito, que a empresa afirma utilizar.

A média da Gestão da Cadeia de Suprimentos teve uma diferença entre a Obra 3 e as outras obras. Enquanto as obras 1, 2 e 4 apresentaram, respectivamente, os valores de $45 \%$, $46 \%$ e $43 \%$ de aplicação das práticas dessa categoria, a obra 3 obteve apenas $36 \%$. Isso ocorreu principalmente porque o gestor da Obra 3 foi transferido para esse empreendimento quando ele estava com cerca de $50 \%$ construído não sendo possível colocar em prática algumas das atividades que esse gestor usa.
As práticas relacionadas com a escolha dos fornecedores e processos de compra é feita por uma equipe do escritório da empresa, assim, as notas desses itens foram as mesmas para todos os empreendimentos uma vez que eles usam os mesmos processos de escolha sempre. A empresa só não avalia o histórico do fornecedor no mercado e não desenvolve fornecedores just-in-time.

O padrão de estocagem e manuseio dos materiais segue normativas internas da empresa baseadas nas normas brasileiras, todos os empreendimentos colocam essas normativas em prática. Para todas as obras é feito o estudo do espaço físico com produção do layout do canteiro pelo menos para três etapas da construção.

A média baixa, a empresa apresenta apenas $43 \%$ de práticas aplicadas nessa categoria, se deve ao fato de não existir processos para controlar a distribuição de materiais internamente no canteiro; controlar os custos da cadeia de suprimentos através das perdas com transporte, armazenamento e inspeção dos materiais e controlar o processo de compra. A maioria dos itens desses critérios são feitos usando a experiência pessoal de cada gestor.

A categoria de Planejamento e Controle da Produção foi a que apresentou uma maior diferença entre os gestores. As Obra 2 e Obra 3 obtiveram uma nota superior à média da empresa, registrando um valor de $54 \%$ e $47 \%$, respectivamente, comparados aos $44 \quad \%$ da empresa. Este fato se justifica pelos gestores fazerem o planejamento de longo e médio prazo mais detalhados, indo além das informações passadas pela equipe de planejamento da empresa, como a execução de Gráfico de Gantt e linhas de balanço. Esses gestores aplicam conhecimentos específicos adquiridos no mestrado e no curso de pós-graduação. As demais obras, em que os gestores não executam o planejamento de forma mais detalhada, apresentaram $38 \%$ dos itens dessa categoria. 
A nota baixa da empresa nesta categoria é por causa da falta de execução de gráficos de balanceamento de operações (GBO) e tabelas de trabalho padronizado combinado no planejamento de curto prazo; falta de mapeamento de fluxo de valor e falta de processos específicos para analisar as perdas dos processos produtivos. Essas ferramentas não são aplicadas devido ao desconhecimento sobre elas.

\section{CONCLUSÕES}

Ao final dessa pesquisa, conclui-se que foi possível aplicar a ferramenta Lean Construction Assessment Tool (LCAT). Os quatro empreendimentos da empresa analisada apresentaram um desempenho médio segundo as categorias da ferramenta utilizada. O lean score de cada obra e o da empresa é mostrado no Quadro 5, que mostra o grau de implementação que cada obra e a empresa adquiriram por categoria e o seu nível final.
Como podemos ver pelos valores do quadro acima, a mudança de gestores de um empreendimento para o outro afeta sim a nota final da empresa, mesmo quando ela apresenta processos padronizados. Os processos referentes à Gestão de Projetos como o planejamento do desenvolvimento de projetos, a compatibilização e validação destes, a identificação do valor requerido pelo cliente e a identificação dos problemas de projeto já estão muito bem implementados. No entanto, os processos da Gestão da Cadeia de Suprimentos e do Planejamento e Controle da Produção requerem melhorias pois permitem que cada gestor use as práticas de forma diferente dentro dos canteiros, a uniformização desses processos pode aumentar a produtividade e reduzir custos dos processos executivos.

No caso estudado, houve uma divergência em $25 \%$ dos itens analisados. O lean score da empresa foi de 58\%, que segunda as faixas determinadas por Camargo Filho (2017) significa que a empresa tem um nível médio de implantação lean.

QUADRO 5: Grau de implementação por categoria e total

\begin{tabular}{|l|c|c|c|c|c|}
\hline & Obra 1 & Obra 2 & Obra 3 & Obra 4 & Empresa \\
\hline GESTÃO DA QUALIDADE & $65 \%$ & $64 \%$ & $63 \%$ & $63 \%$ & $64 \%$ \\
\hline GESTÃO DA CADEIA DE SUPRIMENTOS & $45 \%$ & $46 \%$ & $36 \%$ & $43 \%$ & $43 \%$ \\
\hline PLANEJAMENTO E CONTROLE DA PRODUÇÃO & $38 \%$ & $54 \%$ & $47 \%$ & $38 \%$ & $44 \%$ \\
\hline GESTÃO DE PROJETOS & $81 \%$ & $81 \%$ & $81 \%$ & $81 \%$ & $81 \%$ \\
\hline LEAN SCORE & $57 \%$ & $62 \%$ & $57 \%$ & $56 \%$ & $58 \%$ \\
\hline
\end{tabular}




\section{REFERÊNCIAS BIBLIOGRÁFICAS}

APPOLINÁRIO, F. Dicionário de metodologia científica: um guia para a produção do conhecimento científico. São Paulo: Atlas, 2004.

CAMARGO FILHO, C. A. B. LCAT: Ferramenta de Avaliação da Implementação da Construção Enxuta. 2017. 99 f. Monografia (Exame de Qualificação) Programa de Pós Graduação em Geotecnia, Estruturas e Construção Civil, Universidade Federal de Goiás, Goiás, 2017

CARVALHO, B. S. Proposta de uma ferramenta de análise e avaliação das construtoras em relação ao uso da construção enxuta. 2008. 141 f. Dissertação (Mestrado em Engenharia Civil) - Curso de Pósgraduação em Construção Civil, Universidade Federal do Paraná, 2008.

CBIC - Câmara Brasileira da Indústria da Construção. Disponível em: <http://www.cbic.org.br>. Acesso em: 20 set. 2016.

ETGES, B. M. B. S. Protocolo de auditoria do uso de práticas da construção enxuta. 2012. 85 f. Dissertação (Mestrado em Engenharia de Produção) - Programa de Pós-graduação em Engenharia de Produção, Universidade Federal do Rio Grande do Sul, 2012a.

ETGES, B. M. B. S.; SAURIN, T. A.; BULHÕES, I. R. A protocol for assessing the use of lean construction practices. In: 21th Annual Conference of the IGLC, Fortaleza, Brazil. Proceedings... Fortaleza, Brazil. 2013.

ETGES, B. M. B. S.; SAURIN, T. A.; BULHÕES, I. R. Identifying lean construction categories of practices in the IGLC proceedings. In: 20th Annual Conference of the IGLC, San Diego, USA. Proceedings... San Diego, USA. 2012b.

GIL, A. C. Como elaborar projetos de pesquisa. 3. ed. São Paulo: Atlas, 1991.

HOFACKER, A.; FERNANDES, B.; GEHBAUER, F. FREITAS, M. C. D.; MENDES, R.; SANTOS, A.; KIRSCH, J. Rapid lean constructiction - quality rating model. In: 16th Annual Conference of the IGLC, Manchester, UK. Proceedings... Manchester, UK. 2008.

HOWELL, G. A. What is lean construction. In: Seventh Conference of the International Group for Lean Construction, 1999, University of Berkeley, California, EUA. Proceedings IGLC -7, p 1-10.

KOSKELA, L. Application of the new production philosophy to construction. Center for Integrated Facility Engineering. 1992. 87f. Technical Report. Finland VTT Building Technology, Finland, 1992
SALEM, O.; SOLOMON, J.; GENAIDY, A.; MINKARAH, I. Lean Construction: From Theory to Implementation. Journal of Management in Engineering, v. 22, n. 4, p. 168-175, 2006.

SEBRAE - Serviço de Apoio às Micro e Pequenas Empresas. Disponível em: <http://www.sebraesc.com.br/leis/default.asp?vcdtexto=4154>. Acesso em: 19 jun. 2017.

SILVA, R. S. M.; AMARAL, T. G.; SILVA, F. M. A. Fuzzy logic applied to lean construction - An implementation in building companies. Journal of Civil Engineering and Architecture Research. v. 1, n. 1, p. 37-44, 2014.

VALENTE, C.; NOVAES, M.; MOURÃO, C. A.; NETO, J. Lean monitoring and evaluation construction site: a proposal of lean audits. In: 20th Annual Conference of the IGLC, San Diego, USA. Proceedings... San Diego, USA. 2012.

WOMACK J.; JONES D. e ROOS D. A máquina que mudou o mundo - Rio de Janeiro: Campus, 2004.

WOMACK, J. P.; JONES, D. T. Beyond Toyota: How to root out waste and purse perfection. Harvard Business Review. v. 74, n. 5, p. 140-158, Sept./Oct. 1996.

YIN, Robert K. Estudo de caso - planejamento e métodos. 2 ed. Porto Alegre: Bookman. 2001. 